\title{
Current trends in the development of automation surveying support in the construction of subways
}

\author{
Abduboki Khakimov ${ }^{1, *}$, Gullola Kutumova $^{1}$, and Zamira Mirzaeva ${ }^{2}$ \\ ${ }^{1}$ Tashkent State Technical University, 100095, Tashkent, University Str., 2, Republic of Uzbekistan \\ ${ }^{2}$ Tashkent Institute of Engineers of Railway transport, 100067, Tashkent, Adilkhodjaev Str., 1, \\ Republic of Uzbekistan
}

\begin{abstract}
The article discusses the basic principles and conditions for the use of the latest underground navigation system. An example is given of the second new Yunusabad line of the Tashkent Subway using the shield method. For the first time in the Republic of Uzbekistan, in the construction of the Tashkent metro stations by underground, the Tunneling Mechanized Complex (TMC) was used - a movable prefabricated metal structure manufactured in Germany by the company HERRENKNECHT, which is the leading company in the world and produces machines for the construction of tunnels of any diameter in the range from 0.10 to $19 \mathrm{~m}$ in any engineering-geological conditions. The disadvantages and advantages of the underground navigation system are indicated; conclusions are drawn about the prospects for its application. The patterns of development of technical aspects of the automation of surveying concerning general historical trends are examined.
\end{abstract}

\section{Introduction. The development of the surveying support system in the construction of the Subway}

One of the most important directions in the development of the mine surveying support system is the creation of a technical base that would make it possible to fully utilize the capabilities of electron-optical and computer technology, economic and mathematical methods, and information technology to increase the efficiency of accounting and control of mining operations and the validity of decisions made. An integrated approach to solving the problems of surveying and the use of accurate quantitative methods and computer technology in the production of surveying operations are the main components of the process of automating surveying support for mining and create entirely new conditions for its implementation [4]. Automation in surveying is not only an instrument of selfimprovement, but also raises all mining production to a higher level. Many years of experience in introducing and operating new surveying technologies using electron-optical and gyroscopic systems gives enough reason to conclude that their use, especially when working in hard-to-reach mountain regions of Uzbekistan, in urban conditions, is not only

*Corresponding author: alyanizamova@umal.uz 
economically justified, but often it is the only a possible mean of quick execution of work with the least expenditure of physical labor [8]. During design and construction, the structure of the massif, the physicomechanical properties of rocks, their change in time, the seismicity of the region, maximum loads, etc., are taken into account. Tunnels are an essential link in the construction of underground engineering structures related to the growth and development of the national economy. In this regard, surveying works are widely used in tunneling. Geodetic surveying work is a responsible process at all stages of the construction of subways [10]. The quality, timing and operational effect of the use of facilities under construction largely depend on the timely and high-quality implementation of geodetic-surveying work. Research in this area helps to achieve higher accuracy, both in observation and in calculations. New developments allow us to automate the work in the tunnel and contribute to reducing the time spent on measuring angles and distances [5]. During the construction of the subway tunnels, after the installation of the tunnel rings, various kinds of deformation arise. To ensure a trouble-free operation of the subway, it is necessary to conduct constant and high-precision geodetic observations of the Development of deformations of underground metro structures. A significant point for ensuring integrated safety in mining is to control the stability of the earth's surface, buildings, and structures located in areas affected by mine workings, sides of quarries, and predicting their behavior. Today, deformational monitoring of the state of natural objects and artificial structures is a necessity and an integral part of an integrated security system [6].

The level of modern equipment, the latest communication tools, powerful computing systems, and software products allow to design and create Automated Deformation Monitoring Systems (ADMS). Depending on the construction scheme adopted in severe geological conditions, the excavation of the workings of a broadcross-section can be carried out by continuous slaughter or in parts when mining works are carried out at different horizons. The task of the surveying service, in this case, is to ensure the exact closure of the lining elements, erected simultaneously in different parts of the structure. Therefore, the task of directions during the excavation of mine workings in the horizontal and vertical planes is combined with the simultaneous execution of a set of alignment works both during the hole and the erection of the lining. Besides, when cutting underground chambers of broad crosssection, there is also a need for monitoring the stability of temporary filling and subsurface structures. The highest requirements for the accuracy of the alignment work are imposed during the installation of sophisticated underground energy, transport, and other equipment. Modern high-speed mining methods for underground mining require the use of new, more advanced methods of surveying control, providing high performance and accuracy of measurements. On extensive use of modern laser mine-surveying instruments at all stages of civil engineering and surveying so that because giving the necessary support to install and installation of process equipment in current conditions is possible only through the use of laser methods. Based on the preceding, it can be concluded that improving the methods of surveying in underground construction using laser devices is an urgent task [9].

\section{Methods}

\subsection{Modern methods and means of mine surveying during the construction of a new line "Tashkent subway" using the shield method}

In the design, construction, and operation of tunnels, it is necessary to solve complex scientific, engineering, and environmental problems using the latest achievements of science and technology. The art of modern tunneling is precisely to use and correctly combine the necessary developments that exist in the world. In engineering works related to 
the installation and construction of tunnels, new technologies and materials are widely used. The use of new high-performance equipment allows them to be performed in a shorter period, which helps to reduce the time of commissioning of facilities. The most illustrative example of the Development of innovative technologies is the use of advanced highperformance mining equipment. For the first time in the Republic of Uzbekistan in the construction of the subway stations of the Tashkent underground methods applied Tunneling Mechanized Complex (TMC) - movement prefabricated metal structure, made in Germany, "Companies HERRENKNECHT" AG. Concern "HERRENKNECHT" AG recognized world leader in the field of mechanized tunneling equipment. This is the world's leading company that produces machines for the construction of tunnels of any diameter in the range from 0.10 to $19 \mathrm{~m}$. Subway builders had at their disposal a pickaxe, a shovel, and a trolley. Today, builders have the most advanced technology in their arsenal. Tunnels are laid by individual machines - tunneling mechanized complexes or shields. Tunnel construction has always been an extremely complex engineering challenge. Hard rocky soils, soft clays, and loose sands, aquifers that can flood the space underground in a matter of minutes, are waiting for the walkers. Solid not only dig underground passage but also reinforce it, leaving a ready-tunnel. The iron concrete ring formed of five main RC tubings, each weighing $3200 \mathrm{~kg}$ and locking tubing $500 \mathrm{~kg}$, the weight of the whole ring $16500 \mathrm{~kg}$. Forward movement of the machine provides a tunneling machine overcomes 10 to 12 meters per day in the construction of the tunnel. Pass 250-300 meters per month is considered a good indicator of the builders. After the underground passage is entirely ready, the builders lay the rails and bring engineering networks. The usual distance between stations is $2-2.5 \mathrm{~km}$. A sabway train travels this distance in three minutes (Fig.1).

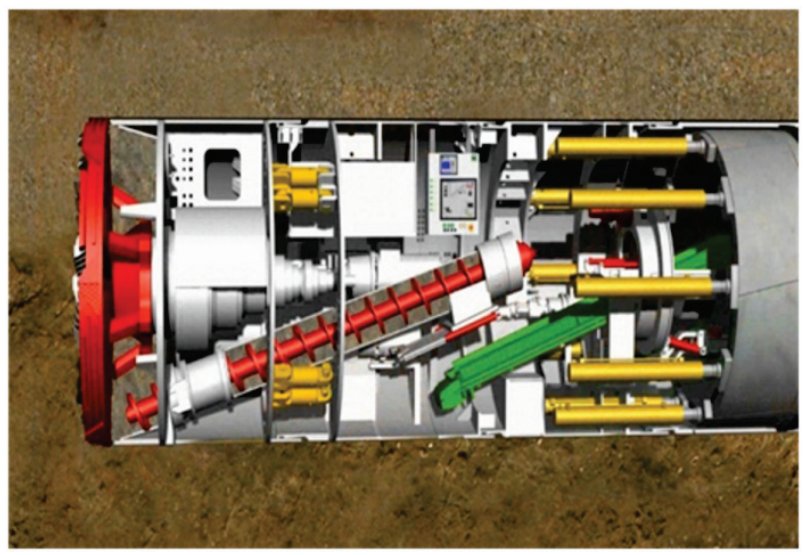

Fig. 1. The head part Knife, the support ring, and the tail of the shield.

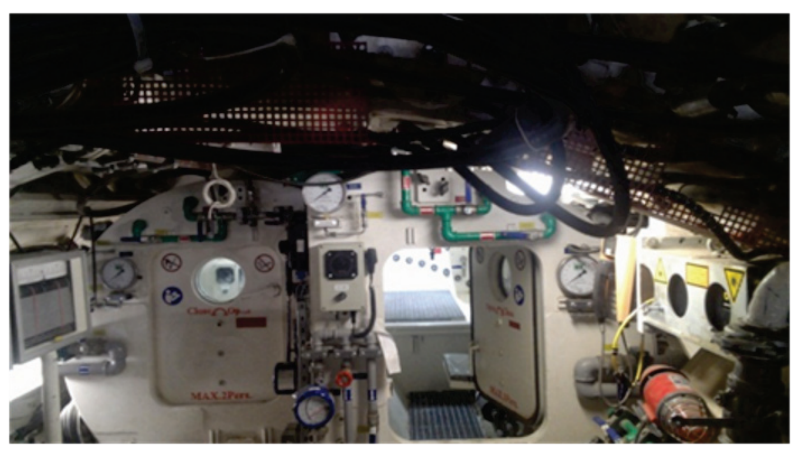

Fig. 2. Airlock shield chamber (Tashkent-2018). 
The path underground is laid by the most accurate navigation electronics; with its help, the shield surveyor checks the designcoordinates of the track in plan and profile. After the tunnel is laid, the tunneling equipment will be used when putting other under ground lines shields with soil loadmainly used for the consistency of the soil from porridge to soft. The breed itself, developed with the help of a working body, acts as a medium for the cargo. Ground with the addition of conditioning agents is converted into "porridge" and is used to maintain the face breast. On the screw, reaching the bottomhole chamber, the soil is fed in the direction from the chest of the face. From the auger, the developed rock gets to the conveyor belt, with the help of which it moves to the loading station of the transport trolleys. The installation of the tunnel reinforced concrete lining is carried out using the block stacker in the sequence, the control panel of the block stacker switches to the "ring mounting" operating mode, after which it is allowed to control the driving jacks when using the control unit of the block layer. Blocks are transported to the block layer utilizing a block storage unit [3] (Fig. 3-4).

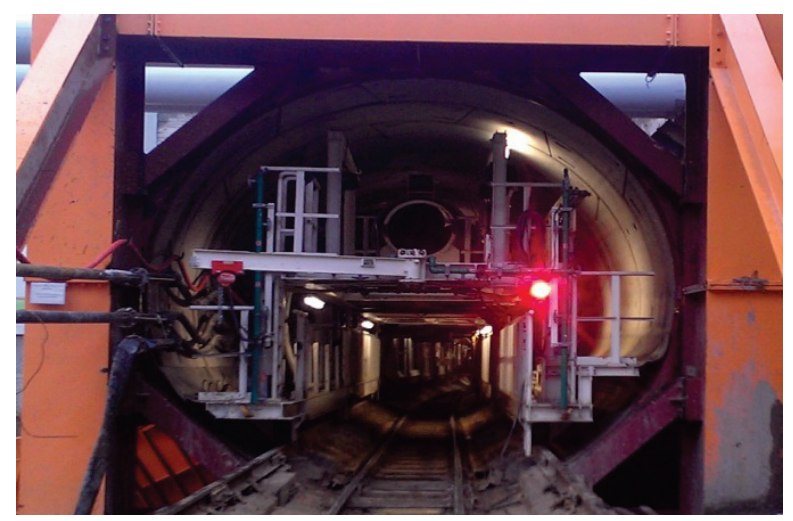

Fig. 3. The tail of the technological shield trolley (Tashkent-2018).

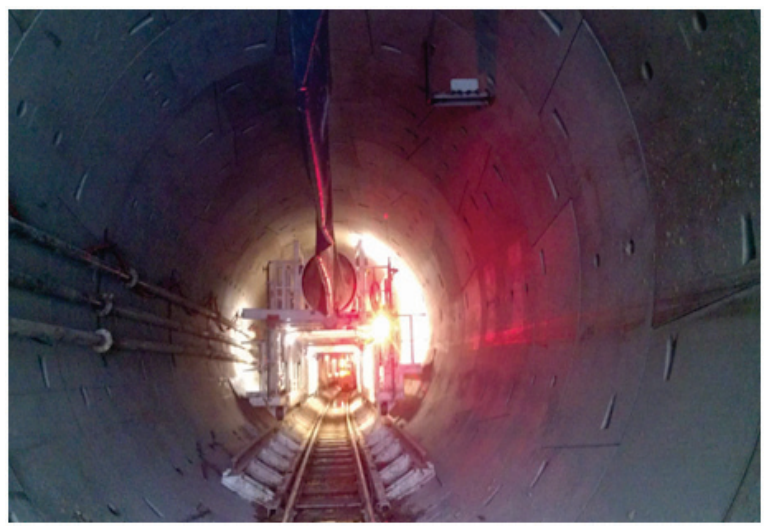

Fig. 4. Finished high-quality tunnel lining (Tashkent-2018).

The injection of grouting mortar into the construction gap between the soil and the lining of the tunnel ensures the geometric immutability of the coating, the joint work of the filling with the surrounding soil, prevents the settlement of the surface during sinking, ensures the safety of the lining and increased water resistance for the period of operation of the tunnel [1].

The solution to the issues of intensive Development of the subway is impossible without a sharp increase in labor productivity, strengthening engineering preparation of production, 
and, most importantly, without accelerating the scientific and technological progress of industries of all types of work. Modern information technologies, high-tech equipment, and ambitious projects, which are often on the verge of possible, all this leads to the appearance of new developments that make the construction of tunnels safer, more economical, and more diverse.

\subsection{Underground laser navigation system "SLS-SL" of the German company "VMT" GmbH for (TMC) "HERRENKNECHT" AG}

The problem of determining the location under the ground appeared almost simultaneously with the idea of developing underground space. At present, when building tunnels for various purposes, automatic navigation systems have become widespread. They allow to determine the spatial position of the tunneling complex in real-time, which significantly increases the speed, accuracy, and quality of the structure under construction [1]. When constructing tunnels, it is essential all the time to have information on the position of the tunnel complex relative to a given tunnel path. Only by continually monitoring the situation of the (TMC) it is possible to consistently and continuously correct unwanted displacements of the tunnel shield and thereby prevent deviations of the protection from the projected axis of the tunnel. Many differences affect the differences from a given path: for example, soil structure (rocky, sandy, clay, etc.). In soft rocks, a tunneling complex weighing hundreds of tons does not react at all like in hard stones [4]. "The VMT" GmbH - surveyorgeodetic service for the Development of an underground navigation system for tunneling, is a company that started in April 1994. The SLS - SL navigation system is designed for tunnel shields with tubing lining, the principle of the system: when the Tunneling complex is moving, the current position of the target is continuously read from the system automatic tachometer, and the exact location of the machine is displayed through its ratio with the projected axis of the tunnel. The next step in the construction of tunnels with tubing lining is the construction of the tubing ring itself in the tail of (TMC). The choice of the most suitable ring is of great importance, which determines the quality of the entire tunnel structure in the future. If the machine deviates from the design axis, the program automatically calculates the corresponding correction curve, which ensures the removal of the device to the planned design axis. In addition to calculating the position of the rings and the order of their construction, as the work progresses, for the development of a tunnel with tubing lining to ensure high-quality construction and guarantee its safety [2].

The navigation system SLS ( Space Launch System ) of VMT, which transmits all the information needed to move the (TMC) along a given track at high speed, was developed specifically for this purpose. Besides, she issues full documentation describing the movement of the shield and a lot of additional information, for example:

- calculation and depiction of the position of (TMC) in graphic and digital form;

- calculation and image of the installed rings, showing the location of the collar after its installation;

- prediction and model of (TMC) displacement trends (shield diagram);

- calculation of a correction curve tangentially leading (TMC) back to a given path;

- preliminary calculation of the tubing rings to be installed in the future (based on the route and the correction curve);

- management of system elements from an industrial computer;

- full documentation on the progress of the shield (database, log files, etc.)

The navigation system SLS - SL includes: a total station with a built in laser (Fig. 5); radio modem No.1 (mobile) (Fig. 5); active Laser Target (ELS) (Fig. 7); radiomodem No. 2 
(motionless) (Fig. 8); Central Radio Modem (switch) (Fig. 9); industrial computer with Tunis software (Fig. 10); prism reflector (Fig. 6); power Cables.

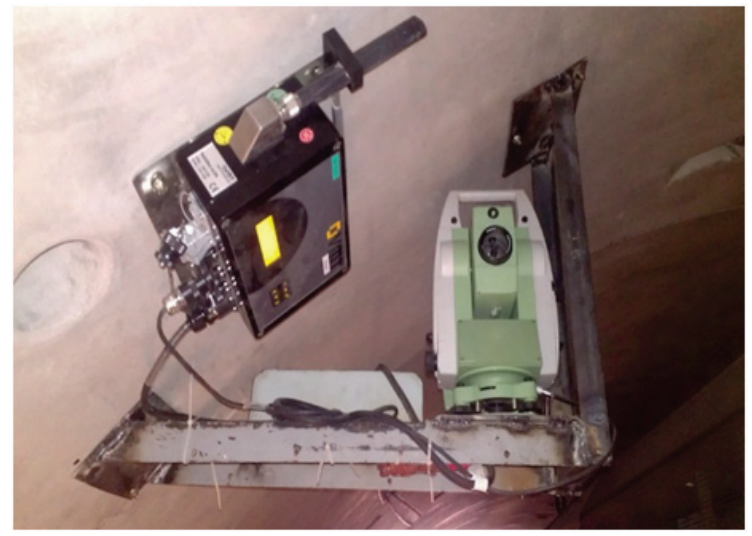

Fig. 5. Half-robot laser total station and Radio modem (mobile). (Tashkent-2018).

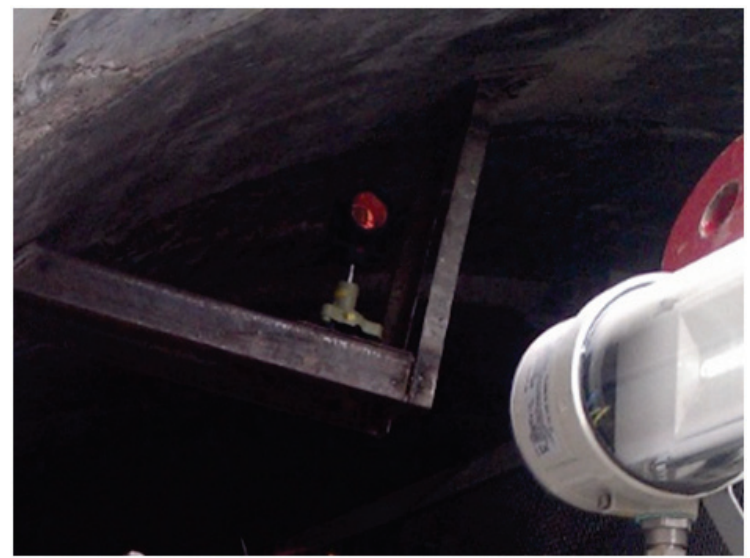

Fig.6. Prism - a reflector on the console. (Tashkent-2018).

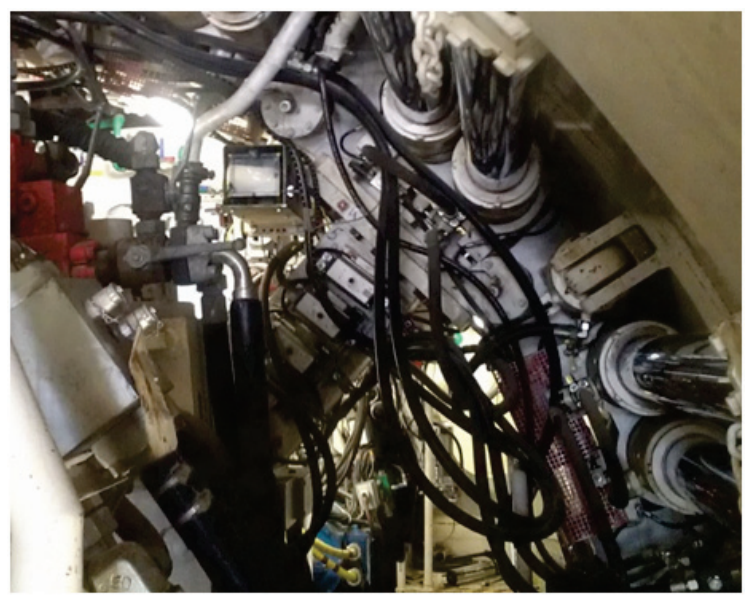

Fig. 7. Active laser target inside the shield. (Tashkent-2018). 


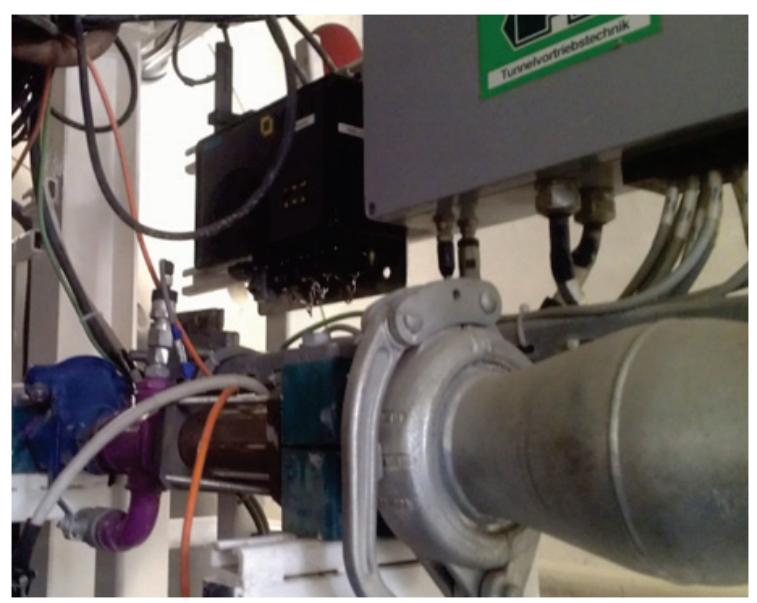

Fig. 8. Radio modem (fixed). (Tashkent-2018).

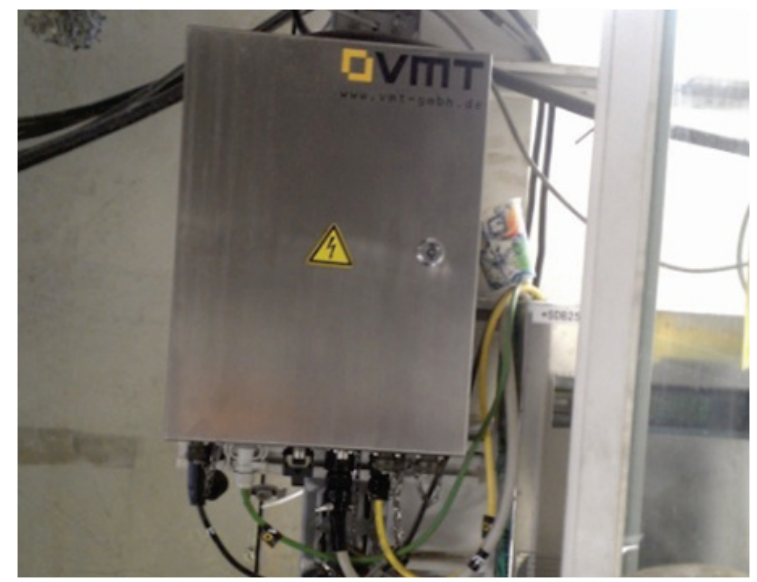

Fig. 9. Central Radio Modem (Switch). (Tashkent-2018).

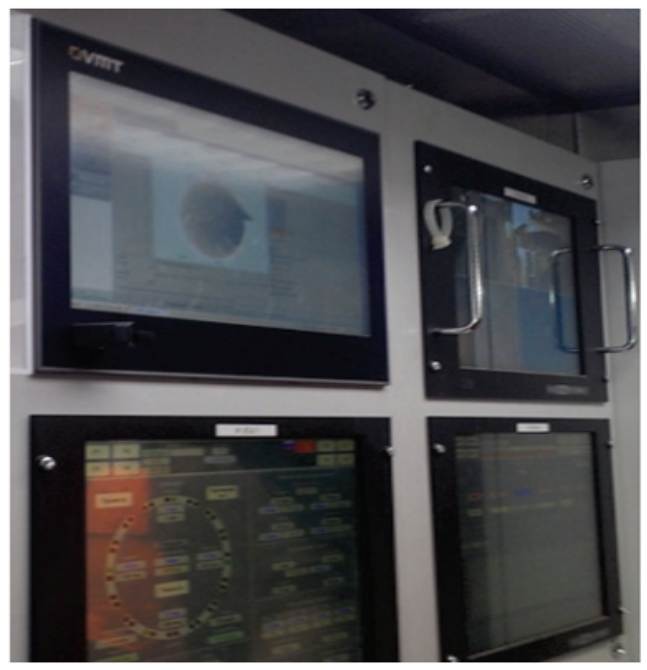

Fig. 10. Industrial computer "VMT" (Tashkent-2018). 
After orienting the laser total station relative to the backsight point (prism reflector), the entire station is automatically aimed at the laser target mounted inside the shield, the signals from the target are transmitted through the laser station through the channels of the Radio modem to an industrial computer in the control panel, the total laser station measures horizontal and horizontal angles at the points also the distance, there the data of these measurements are presented on the monitor in graphic and digital format. Tunis (Tunnel and Under ground integrated Software) is an integrated software platform for preparing and analyzing data in tunnel and subway construction projects [2].

The introduction of an underground navigation system into the surveying practice was an essential for the further development of the techniques and methods of underground surveys. It is impossible to judge the accuracy of measuring angles and the distance of underground surveying points by the result of the navigation system of the tunneling mechanized complex. Mine surveying should be carried out in such a way that reliable surveying and individual surveying measurements are carried out the control.

\section{Conclusions}

The introduction of an underground navigation system into the surveying practice is of great importance for the development of underground surveying methods. The use of the latest underground navigation system in the construction of the Tashkent Subway in the field of new electron-optical measuring instruments qualitatively changed the speed of surveying operations, and increased the accuracy of measurements.

The advantage of the underground system SLS-SL of VMT GmbH provides real-time information on the position of the tunnel complex, which significantly increases the speed, accuracy and quality of the structure under construction.

\section{References}

1. Instructions for geodetic and surveying work in the construction of Transport tunnels, UBC 160-69

2. Guide to the activities of the company " VMT " GmbH and the underground navigation system). Retrieved from: https://cyberleninka.ru/article/n/o-deyatelnosti-firmy-vmt$\mathrm{gmbh} /$ viewer

3. Materials of publications and information retrieved from the Web site of the "HERRENKNECHT" AG Company. Retrieved from: https://www.herrenknecht.com.

4. Kartosia, B.A., Fedunets, B.I., Shuplik, M.N., Malyshev, Y.N. et al (2001). Mine and Underground Construction: 2nd ed. in 2 vol. Moscow: Academy of Home Sciences

5. Popov, V.N., Bukrinsky, V.A. (2004). Geodesy and Mine Surveying. Moscow: Publishing House of Moscow State University

6. Pevzner, M.E., Popov, V.N., Bukrinsky, V.A. (2003). Mine surveying. Moscow: Publishing House of Moscow State University

7. Evstafiev, O.V., Yaschenko, A.I. (2010). Problems of installation and safety of equipment of automated monitoring systems, Geoprofi, 2

8. Instructions for the production of surveying operations. (2004). RD 07-603-03

9. Geodetic instruments and equipment. (2003). Catalog: Moscow: NPP

10. Eremenko, E.V. (2012). The formation of cargo flows, overburden taking into account the location. human-made resource career. Coal, 9. Moscow: Mountain Book 